\title{
Hip reconstruction in patients with ischemic deformity of the proximal femur and associated acetabular dysplasia
}

\author{
M.P. Teplenky, E.V. Oleinikov, V.S. Bunov
}

Ilizarov National Medical Research Centre for Traumatology and Orthopedics, Kurgan, Russian Federation

\begin{abstract}
Introduction Acetabular dysplasia associated with ischemic deformity of the proximal femur leads to significant functional limitations and progressive hip osteoarthritis $(\mathrm{OA})$. The best surgical approach, the timing and the volume of surgery are still controversial. Material and methods Outcomes of 32 patients with ischemic hip deformity were reviewed. The mean age at the time of surgery was $15.8 \pm 0.7$ (range, 12-24) years. The mean follow-up period was $4.2 \pm 0.4$ years. Clinical outcomes were measured using the Merle d'Aubigné-Postel, Tönnis, Severin scoring scales and the grading system developed at the National Ilizarov Medical Research Center for Trauma and Orthopedics (NIMRC TO). Extra-articular $(n=24)$ and intraarticular $(\mathrm{n}=8)$ procedures were produced for hip reconstructions. Results The hip function score was $5.2 \pm 0.1$ after extraarticular interventions and $4.3 \pm 0.14$ after intra-articular procedures. Postoperatively, hip joints were + graded as Severin IIa $(\mathrm{n}=18)$, Severin IIb $(\mathrm{n}=10)$ and Severin III $(\mathrm{n}=4)$. No arthritic changes occurred in 25 hips. In the remaining cases, OA either progressed $(n=4)$ or improved $(n=3)$. Outcomes were rated as good with $2.6 \pm 0.03$ scores $(n=17)$, fair with $2 \pm 0.1$ scores $(\mathrm{n}=13)$ and poor with $1.41 \pm 0.05$ scores $(\mathrm{n}=2)$ measured on the NIMRC TO scale. Conclusion The technologies offered for the reconstruction of both articular components have been shown to be effective in treatment of patients with ischemic hip deformity and associated acetabular dysplasia.
\end{abstract}

Keywords: Perthes disease, ischemic deformity, acetabular dysplasia

\section{INTRODUCTION}

Residual ischemic deformities of the hip joint are associated with underlying etiologies such as Perthes disease, avascular necrosis of the femoral head following treatments of the hip dysplasia. Major manifestations of the pathology include flatenning of the femoral head, hyperplasia of the greater trochanter, primary or secondary acetabular dyspasia [1]. These pathological characteristics are indicative of less contacting area between the articular surfaces, increase in intra-articular pressure and cause progression of arthritis in childhood [2]. There are controversies regarding surgical treatment of the deformities. It is still unclear whether the femoral deformity and dysplastic acetabulum should be addressed in one or two surgical sessions [1]. Combined intra-artcular procedures performed for both articular components are associated with a greater risk of complications and poor outcomes [3]. Clohisy reported no major differences in outcomes of combined extra-articular procedures and standalone hip reconstruction despite severe abnormalities at baseline [4].

The purpose of the study was to review shortand mid-term results of reconstructive procedures performed for both articular components in patients with ischemic hip deformities and associated acetabular dysplasia.

\section{MATERIAL AND METHODS}

Outcomes of 32 patients were reviewed. The mean patients' age at the time of surgery was $15.8 \pm 0.7$ years (range, 12-24). The mean follow-up period was $4.2 \pm$ 0.4 years. Inclusion criteria were ischemic deformity of the proximal femur of different origin, impaired congruency of the articular surfaces, primary and secondary acetabular dysplasia, absence or initial signs of arthritis, follow-up period of at least two years. Exclusion criteria were Tonnis grade III arthritis, follow-up period of less than two years. The deformity of the proximal femur was caused by DDH $(n=20)$ and Perthes disease $(n=12)$. Clinical outcomes were measured using the Merle d'Aubigné-Postel grading system [5] evaluating pain, range of motion in the joint and the gait. Anteroposterior views and false profile hip radiographs were analyzed for hip pathology. Radiographic parameters evaluated included acetabular weight-bearing surface (WBS), Idelberger-Frank angle, acetabular sphericity index (ISA) and head sphericity index (ISH) (ratio between the diameter of the circumference corresponding to the shape of the articular component to half-distance between teardrops), articulo-trochanteric distance (ATD), articular surface congruency index (ICAS - ISA/ISH ratio), Wiberg 
angle (CEA), vertical-central angle (VCA), acetabularhead index (AHI), cranial displacement (SL), lateral displacement angle (LDA). Severity of arthritis was rated with Tönnis grading system [6]. Modified Coleman scores were used to evaluate the articular surfaces. Four types of congruency were identified: type I, spherical congruent articular surfaces (ISA 0.8-1.2, ISH 0.6-1.0, ICAS 1.1-1.4); type II, spherical incongruent articular surfaces (ISA $>1.5$, ISH 0.5-1.0, ICAS > 1.5; ISA 1.3-1.4, ISH 1.4-1.6, ICAS 0.9-1.0); type III, nonspherical congruent articular surfaces (ISA 1.3-1.8, ISH 1.2-1.7 ICAS 1.0-1.3); type IV, nonspherical incongruent articular surfaces (ISA 1.31.5, ISH 1.4-1.6, ICAS $<1.0$ ).

Joint preservation reconstructive surgeries performed for the patients relied on the type of congruency of the articular surfaces and ICAS angle (Fig. 1). Pelvic osteotomy (PO, 22 hips) was used for acetabular transposition and added by imcomplete periacetabular osteotomy $(\mathrm{PO}+\mathrm{PAO})$ for acetabular reshaping [7, 8]. Pelvic osteotomy was supplemented with acetabuloplasty $(\mathrm{PO}+\mathrm{AP})$ to increase volumetric size of the acetabulum. Acetabuloplasty was used as a standalone procedure in one case. Proximal femur reconstruction (PFR) involved transposition of the greater trochanter (8 hips), double transtrochanteric osteotomy (11 hips), intertrochanteric correction osteotomy (6 hips). Articular procedures were added with intra-articular interventions $(n=8)$ including surgical dislocation of the femur (SDF), head reduction osteotomy (HRO, 4 hips) or remodeling resection of the head (MRH, 4 hips). Osteotomized fragments and the hip joint were secured with the Ilizatov extrenal fixator. Decompression of the articulation was provided during treatment. The length of treatment with frame on was $78 \pm 3.2$ days. Compression screws were used to fix the head and the trochanter in intra-articular procedures and fixation with the frame on lasted for $33 \pm 1.5$ days. Rehabilitation period was $10 \pm 1.2$ days. Neither infection nor neurologic deficiency were noted in the study group. Fracture of the femoral neck occurred during capital osteotomy in one case and was fixed intraoperatively and made no substantial effect on the course of rehabilitation.

Functional outcomes were measured using the Merle d'Aubigné-Postel scale and the Severin, Tönnis [6] scoring scales and the grading system developed at the National Ilizarov Medical Research Center for Trauma and Orthopedics (NIMRC TO) were used for radiological assessment (Table 1).
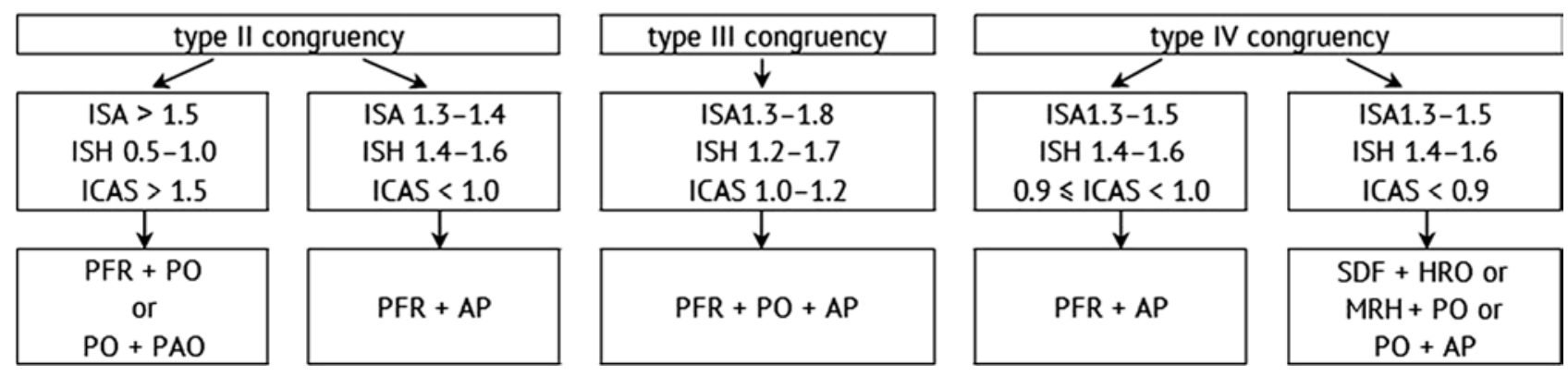

Fig. 1 Algorithm of joint preservation procedure to correct ischemic deformity of the proximal femur and associated acetabular dysplasia

Table 1

Evaluation of radiographical parameters in patients with dysplastic coxarthrosis

\begin{tabular}{|c|c|c|c|}
\hline Radiometric parameter & 3 scores & 2 scores & 1 score \\
\hline AI (WBS angle),$^{0}$ & $5-15(0-10)$ & $16-20(11-15)$ & $>20(>15)$ \\
\hline $\mathrm{AIF}^{\circ}$ & $40-50$ & $51-65$ & $>65$ \\
\hline ISA & $0.8-1.25$ & $1.26-1.5$ & $>1.5$ \\
\hline Femoral head & $\begin{array}{l}\text { Improved or no changes } \\
\text { occurred }\end{array}$ & The shape impaired & $\begin{array}{c}\text { The shape and structure } \\
\text { impaired }\end{array}$ \\
\hline ISH & $0.6-1.0$ & $1.1-1.5$ & $>1.5$ \\
\hline ATD, mm & $>10$ & $0-10$ & $<0$ \\
\hline AHI & $1.0-0.85$ & $0.84-0.65$ & $<0.65$ \\
\hline ICAS & $1.0-1.4$ & $>1.4$ & $<1.0$ \\
\hline $\mathrm{LDA}^{0}$ & $<20$ & $20-25$ & $>25$ \\
\hline $\mathrm{Sl}, \mathrm{cm}$ & $<0.5$ & $0.5-1.0$ & $>1.0$ \\
\hline Severity of arthritis & $\begin{array}{l}\text { Improved by } 1 \text { score or no } \\
\text { changes occurred }\end{array}$ & Became worse by 1 score & $\begin{array}{l}\text { Became worse by more } \\
\text { than } 1 \text { score }\end{array}$ \\
\hline
\end{tabular}


A good result was rated with a mean score of more than 2.5. An outcome was evaluated as poor with a mean score of less than 1.7. The study was performed in accordance with ethical principles for medical research involving human subjects stated in the Declaration of Helsinki developed by the World Medical Association as revised by Ministry of Health of the Russian Federation. Written informed consent was obtained from all patients for publication of the findings without identifying details.

Microsoft Office Excell 2010 was used to complete data analysis reports. An unweighted subsampling approach was used for quantitative data. The data obtained were summarized as means \pm standard deviations. Statistical analysis was carried out using non-parametric Wilcoxon-Mann-Whitney test.

\section{RESULTS}

Patients were assigned to three groups depending on radiographic manifestations. Group I consisted of 14 patients with type II articular surface congruence. The baseline Merle d'Aubigné-Postel function score was $4.4 \pm 0.05$. Radiological manifestations of the pathology included expressed acetabular dysplasia and decentered femoral head (Table 2). Patients of group I showed considerable increase in the mean congruence index. All the cases demonstrated excessive femoral neck anteversion measuring $43 \pm 1.3^{\circ}$. In addition to that, valgus and torsion deformity was observed in 3 cases (NSA $144 \pm 1.5^{\circ}$, ATD $21.3 \pm 0.9)$. Ten patients had coxa vara, short femoral neck, high riding apex of the greater trochanter (NSA $96.5 \pm 2.3^{\circ}$; ATD, $9.8 \pm 2 \mathrm{~mm}$ ). Hip dislocation was graded as Tonnis type I $(n=3)$, Tonnis type II $(n=7)$ and Tonnis type III $(n=4)$ [6]. Hip arthritis was graded as Tonnis type $0(n=7)$, Tonnis type I $(n=4)$ and Tonnis type II $(n=3)$.

Group II consisted of 10 patients with type III articular surface congruence. The baseline Merle d'Aubigné-Postel function score was less than that in Group I measuring $4.04 \pm 0.14$. Radiological manifestations of the pathology included proximal femur deformity in the form of shortened femoral neck and high riding apex of the greater trochanter (ATD, $5.4 \pm 2.2 \mathrm{~mm}$ ). Mean head sphericity index was greater than that in Group I. Acetabular underdevlopment and proximal displacement of the head was less than that in Group I with no statistically significant differences noted (Table 2). Hip dislocation was graded as Tonnis type I $(\mathrm{n}=3)$, Tonnis type II $(\mathrm{n}=6)$ and Tonnis type III $(n=1)$. Hip arthritis was detected in two thirds of the cases and graded as Tonnis type $0(n=3)$, Tonnis type I $(n=5)$ and Tonnis type II $(n=2)$.

Group III consisted of 8 patients with type VI articular surface congruence. The baseline Merle d'Aubigné-Postel function score was much worse than that in Groups I and II due to limited motion in the joint measuring $3.5 \pm 0.12$. Major radiological manifestations of the pathology included decentered femoral head due to severe capital deformity and acetabular dysplasia (Table 2). All patients showed proximal femur deformity in the form of shortened femoral neck and hyperplastic greater trochanter (ATD, $4.3 \pm 0.2 \mathrm{~mm}$ ). The mean congruence index was less than 1.0. All the cases demonstrated excessive femoral neck anteversion measuring $43 \pm 1.3^{\circ}$. Hip dislocation was graded as Tonnis type $I(n=1)$ and Tonnis type II $(n=7)$. Initial signs of hip arthritis were revealed in the group and were graded as Tonnis type $0(n=2)$ and Tonnis type $I(n=6)$.

At a follow-up, the highest Merle d'AubignéPostel function score was observed in Group I measuring $5.4 \pm 0.07$ (plus 1 score). The mean Merle d'Aubigné-Postel function score increased by 0.9 in Group II measuring $4.97 \pm 0.16$. The mean Merle d'Aubigné-Postel function score measured $4.3 \pm 0.14$ in Group III. Statistically significant improvement in the acetabulum and articular relationships was seen radiologicall in all the groups (Table 2). Radiographically, hip joints were graded as Severin IIa $(\mathrm{n}=10)$, Severin IIb $(\mathrm{n}=2)$ and Severin III $(\mathrm{n}=2)$. Severity of arthritis remained unchanged $(n=4)$, progressed to one grade $(n=1)$ and improved $(n=2)$. Hip joints were graded as Tonnis type $0(n=6)$, Tonnis type I $(n=7)$ and Tonnis type II $(n=1)$. Articular surface congruency appeared to improve in 10 hip joints. Hip congruency was graded as Coleman type I $(\mathrm{n}=8)$, Coleman type II $(\mathrm{n}=2)$ and Coleman type III $(n=4)$. The results were rated as $\operatorname{good}(n=9$; $2.7 \pm 0.03)$ and fair $(n=4 ; 1.98 \pm 0.08)$ using the grading system developed at the NIMRC TO. A poor outcome was observed in one case (1.46). There were overall $64.3 \%$ good outcomes in Group I.

Radiographically, hip joints were graded as Severin IIa $(n=6)$, Severin IIb $(n=3)$ and Severin III $(n=1)$ in patients of Group II. Severity of arthritis remained unchanged $(n=8)$, progressed to one grade $(n=1)$ and improved $(n=1)$. Hip joints were graded as Tonnis type $0(n=3)$, Tonnis type $I(n=5)$ and Tonnis type II $(n=2)$. The results were rated as good $(n=6 ; 2.56 \pm 0.01)$ and fair $(n=3 ; 2.1 \pm 0.05)$ using the grading system developed at the NIMRC TO. A 
poor outcome was observed in one case (1.36). There were overall $60.0 \%$ good outcomes in Group II.

Radiological results were shown to be worse in patients of Group III, and hip joints were graded as Severin IIa $(n=2)$, Severin IIb $(n=5)$ and Severin III $(n=1)$. Severity of arthritis remained unchanged $(n=6)$ and progressed to one grade $(n=2)$. Hip joints were graded as Tonnis type $0(\mathrm{n}=2)$, Tonnis type I $(n=4)$ and Tonnis type II $(n=2)$. Hip joint congruency was graded as Coleman type III $(\mathrm{n}=7)$ and Coleman type VI $(\mathrm{n}=1)$. The results were rated as good $(\mathrm{n}=2$; $2.55 \pm 0.01)$ and fair $(n=6 ; 2.03 \pm 0.04)$ using the grading system developed at the NIMRC TO. No poor outcomes were observed with overall good outcomes of $25.0 \%$.

Arthritis progressed by one score in four cases of the group. Impaired congruency persisted in 3 hip joints. There were $53 \%$ good results and $6.3 \%$ poor results.

Table 2

Dynamics in radiometric parameters of 32 patients with ischemic deformities of the proximal femur

\begin{tabular}{|c|c|c|c|c|c|c|}
\hline \multirow{3}{*}{$\begin{array}{l}\text { Radiographic } \\
\text { parameters }\end{array}$} & \multicolumn{6}{|c|}{ Groups of patients } \\
\hline & \multicolumn{2}{|c|}{ group I (14 hips) } & \multicolumn{2}{|c|}{ group II (10 hips) } & \multicolumn{2}{|c|}{ group III ( 8 hips) } \\
\hline & pre-op & at follow-up & pre-op & at follow-up & pre-op & at follow-up \\
\hline WBZ & $39 \pm 3.3$ & $6 \pm 2.3^{*}$ & $34.6 \pm 4.6$ & $9 \pm 2.1^{*}$ & $27.7 \pm 2.3$ & $4.8 \pm 2.3^{*}$ \\
\hline IFA & $63 \pm 2.5$ & $53 \pm 1.9 * *$ & $65 \pm 2.8$ & $55 \pm 1.5 * *$ & $63 \pm 3.7$ & $52.3 \pm 1.2 * *$ \\
\hline ISA & $1.8 \pm 0.13$ & $1.18 \pm 0.07^{*}$ & $1.5 \pm 0.08$ & $1,4 \pm 0.07$ & $1.4 \pm 0.04$ & $1.23 \pm 0.07$ \\
\hline ISH & $0.8 \pm 0.05$ & $0.9 \pm 0.12$ & $1.29 \pm 0.1$ & $1,27 \pm 0.08$ & $1.55 \pm 0.02$ & $1.1 \pm 0.05^{*}$ \\
\hline ATD $(\mathrm{mm})$ & $12 \pm 2.8$ & $10 \pm 1.5$ & $-6 \pm 0.5$ & $7,6 \pm 0.9 *$ & $-4.3 \pm 0.2$ & $10.3 \pm 1.3^{*}$ \\
\hline ICAS & $1.9 \pm 0.12$ & $1.3 \pm 0.1 * *$ & $1.3 \pm 0.07$ & $1,16 \pm 0.03$ & $0.87 \pm 0.03$ & $1.18 \pm 0.04^{* *}$ \\
\hline AHI & $0.47 \pm 0.6$ & $0.9 \pm 0.03 *$ & $0.46 \pm 0.07$ & $0,8 \pm 0.02 *$ & $0.55 \pm 0.02$ & $0.9 \pm 0.04 *$ \\
\hline $\mathrm{CEA}\left({ }^{\circ}\right)$ & $3 \pm 0.8$ & $28 \pm 1.8 *$ & $3.5 \pm 0.4$ & $25 \pm 0.9 *$ & $6 \pm 0.5$ & $22 \pm 1.2 *$ \\
\hline VCA & $10 \pm 3.7$ & $26 \pm 1.2 *$ & $8 \pm 2.3$ & $23 \pm 1.5^{*}$ & $3 \pm 0.7$ & $19 \pm 1.9 *$ \\
\hline $\mathrm{LDA}^{\circ}$ & $37 \pm 2.6$ & $23 \pm 2 * *$ & $35.8 \pm 3.6$ & $25,7 \pm 1.7 * *$ & $34 \pm 2.3$ & $15 \pm 2.8^{*}$ \\
\hline SL mm & $24 \pm 5.1$ & $0.5 \pm 0.2^{*}$ & $18.6 \pm 3.9$ & $2 \pm 1.06^{*}$ & $9.2 \pm 2$ & $2 \pm 1.2^{*}$ \\
\hline
\end{tabular}

${ }^{*}$, significant differences from baseline values, $\mathrm{p}<0.01$; ${ }^{* *}$, significant differences from baseline values, $\mathrm{p}<0.05$

\section{DISCUSSION}

Structural abnormalities developing due to ischemic involvement of the hip joint lead to a complicated pathomechanical environment with the hip being further compromised by concurrent symptomatic femoroacetabular impingement (FAI) and structural instability [9]. These patients were shown to develop coxartrosis during the third and fourth decades of life in $54 \%$ of the cases $[10,11]$. Adolescents and young adults with ischemic deformities are potenial candidates for hip preservation surgeries [9]. The best surgical strategies are still controversial [12,13,14]. Nonsurgical treatment has its role and is vastly considered as preoperative preparation. Surgical options include correcting femoral and pelvic procedures, surgical hip dislocation, osteochondroplasty, transposition of the greater trochanter involving relative lengthening of the femoral neck [4]. Surgical hip dislocation is often described as a primary treatment and diagnosis procedure. Removal of the deformity components contributing to FAI is considered as the basic part of surgical correction. On the contrary, diagnosis and treatment of concomitant acetabular dysplasia remain a controversial issue [15].
Acetabular dysplasia in a Perthes hip results from secondary remodeling with aggravated aspherity of the femoral head. The difference between congenital dysplasia and acetabular dysplasia in a Perthes hip is that the latter is characterized by less severe deficit of the anterior-lateral aspect and horizontal orientation of the acetabulum [16]. The specific features and the irregular femoral head increase a risk of FAI [17]. There is an opinion of decreasing indications for surgical correction of secondary acetabular dysplasia. However, the neglected pelvic component with the deficit of the head coverage left unaddressed can interfere with an outcome of a hip preservation procedure [4]. The opposite point of view supports extra-articular pelvic re-orientation procedure for the treatment of the pathology. T. Shinoda reported good clinical and radiographic mid-term results and delayed progression of osteoarthritis in $94 \%$ of patients with ischemic hip deformities treated with periacetabular osteotomy without combined femoral osteotomies [1]. The authors also suggested that intervention performed for one articular component showed no improvements on articular surface congruence. J.Clohisy et al. 
found it inexpedient to use the parameters set for classical dysplasia in surgical planning of acetabular reorientation in patients with secondary dysplasia [18]. There are controversies regarding accurate indications to hip reconstructions [4]. Anderson et al. detected the best approach with Wiberg angle to measure not less than $16^{\circ}$ [13]. Albers et al. advised to be guided by measurements of the acetabulum $\left(>14^{\circ}\right)$ [19]. Ganz et al. reported indications to pelvic interventions even with $\mathrm{CEA}<25^{\circ}$ and acetabular index measuring $>10^{\circ}$ and increased extrusion by more than $30 \%$ [20]. Recommendations from J. Clohisy et al. are similar to the measurement cited above with the difference in extrusion measuring up to $20 \%$ [9]. All the authors suggested an adequate mobility in the hip joint and the hip congruence as major prerequisites for surgical considerations [4].

We think that CEA angle has no role in patients with ischemic hip deformities due to complexities in identifying the head center. Radiographic parameters that matter include severity of acetabular dysplasia (WBS $>15^{\circ}$ ), head coverage of less than $80 \%$ (parameter being counter to extrusion) and hip congruence. Impaired hip congruence is known as a factor aggravating prognosis of hip preservation surgery [21-23]. Ocano et al. suggested that good acetabular coverage in incongruent hip joint fails to provide a positive result. On the contrary, regained congruence due to surgical correction contributes to favorable course of the pathological process even in baseline osteoarthritis [24].

It should be noted that evaluation of the hip congruence normally involves alterations and ratios in the width of different portions of the articular space with no correlation between the shape and size of articular surfaces to be considered. This can be ascribed to the efforts of surgeons trying to improve joint congruence using femoral intreventions [4, 9, 20]. Pelvic procedure is aimed at spatial acetabular reorientation. This can be effective for Perthes hips and secondary acetabular dysplasia. However, patients with congential hip dysplasia suffer from maloriented acetabulum, thickened bottom and increased vertical size that would require more challenging surgical manipulations. Determination of the shape and size of the articular components and their relationships are deemed to be essential for surgical planning (Fig. 1).

Use of intra-articular procedures as a major tool of correction of ischemic hip deformities has become more common [9, 13, 15, 19, 20, 25]. J. Clohisy suggested that arthrotomy can be used as an isolated manipulation even with pelvic intervention [4]. We opt for extra-articular procedures and suggest that arthrotomy and correcting procedures must be produced for patients with expressed limitation in joint mobility due to hip incongruence and FAI, in minimal radiological signs of arthritis. No statistically significant differences in outcomes of patients of Groups I and II were observed. It allows us to suggest that waiver of intra-articular procedures for irregular femoral head does not lead to FAI and decompensation of the joint. Unloading of the hip can be considered as an additional factor creating environment for mutual adaptation of the articular components. Although patients of Group III showed improved functional score it was shown to be significantly worse as compared to that in Groups I and II and the data reported in the literature $[9,13,19,20]$. This necessitates improvements of the technology. Analysis of outcomes revealed progression of arthritis by one score in $12.5 \%$ of observations. No severe impairments and decompensation of the joints that would require reoperation or conservion to arthroplasty were recorded.

\section{CONCLUSION}

The findings suggest that technologies offered for the reconstruction of both articular components have been shown to be effective in treatment of patients with ischemic hip deformity and associated acetabular dysplasia. Long-term follow-up will be essential for objective evaluation of the surgical effect on the pathological progress.

\section{REFERENCES}

1. Shinoda T., Naito M., Nakamura Y., Kiyama T. Periacetabular osteotomy for the treatment of dysplastic hip with Perthes-like deformities. Int. Orthop., 2009, vol. 33, no. 1, pp. 71-75. DOI:10.1007/s00264-007-0476-9

2. Chen M., Shang X.F. Surgical treatment for young adult hip dysplasia: joint-preserving options. Int. Orthop., 2016, vol. 40, no. 5, pp. 891-900. DOI:10.1007/s00264-015-2927-z

3. Edelstein A.I., Duncan S.T., Akers S., Pashos G., Schoenecker P.L., Clohisy J.C. Complications associated with combined surgical hip dislocation and periacetabular osteotomy for complex hip deformities. J. Hip Preserv. Surg., 2019, vol. 6, no. 2, pp. 117-123. DOI: $10.1093 / \mathrm{jhps} / \mathrm{hnz} 014$ 
4. Clohisy J.C., Ross J.R., North J.D., Nepple J.J., Schoenecker P.L. What are the factors associated with acetabular correction in Perthes-like hip deformities? Clin. Orthop. Relat. Res., 2012, vol. 470, no. 12, pp. 3439-3445. DOI:10.1007/s11999-012-2507-0

5. D'Aubigné R.M., Postel M. The classic: functional results of hip arthroplasty with acrylic prosthesis. 1954. Clin. Orthop. Relat. Res., 2009, vol. 467, no. 1, pp. 7-27. DOI:10.1007/s11999-008-0572-1

6. Tönnis D. Congenital Dysplasia and Dislocation of the Hip in Children and Adults. Berlin, Heidelberg, Springer-Verlag. 1987. DOI: 10.1007/978-3-642-71038-4

7. Teplenky M.P., Oleinikov E.V. Rekonstruktsiia tazobedrennogo sustava u detei shkolnogo vozrasta s vrozhdennym vyvikhom bedra [Reconstruction of the hip in school-age children with congenital hip dislocation]. Genij Ortopedii, 2013, no. 1, pp. 36-39. (in Russian)

8. Shevtsov V.I., Makushin V.D., Teplenky M.P., Atmansky I.A. Sposoby rekonstruktsii displasticheskoi vertluzhnoi vpadiny s pomoshchiu apparata ilizarova [Techniques of dysplastic acetabulum reconstruction using the Ilizarov fixator]. Genij Ortopedii, 2002, no. 4, pp. 5-10. (in Russian)

9. Clohisy J.C., Nepple J.J., Ross J.R., Pashos G., Schoenecker P.L. Does surgical hip dislocation and periacetabular osteotomy improve pain in patients with Perthes-like deformities and acetabular dysplasia? Clin. Orthop. Relat. Res., 2015, vol. 473, no. 4, pp. 1370-1377. DOI:10.1007/s11999-014-4115-7

10.Lecuire F. The long-term outcome of primary osteochondritis of the hip (Legg-Calvé-Perthes' disease). J. Bone Joint Surg. Br., 2002, vol. 84, no. 5, pp. 636-640. DOI: 10.1302/0301-620x.84b5.12124

11. Yrjönen T. Long-term prognosis of Legg-Calvé-Perthes disease: a meta-analysis. J. Pediatr. Orthop. B. 1999, vol. 8, no. 3, pp. 169172. DOI: $10.1097 / 01202412-199907000-00005$

12.Clohisy J.C., Nunley R.M., Curry M.C., Schoenecker P.L. Periacetabular osteotomy for the treatment of acetabular dysplasia associated with major aspherical femoral head deformities. J. Bone Joint Surg. Am., 2007, vol. 89, no. 7, pp. 1417-1423. DOI: 10.2106/JBJS.F.00493

13.Anderson L.A., Erickson J.A., Severson E.P., Peters C.L. Sequelae of Perthes disease: treatment with surgical hip dislocation and relative femoral neck lengthening. J. Pediatr. Orthop., 2010, vol. 30, no. 8, pp. 758-766. DOI: 10.1097/BPO.0b013e3181fcbaaf

14.Tannast M., Macintyre N., Steppacher S.D., Hosalkar H.S., Ganz R., Siebenrock K.A. A systematic approach to analyse the sequelae of LCPD. Hip Int., 2013, vol. 23, no. Suppl. 9, pp. S61-S70. DOI:10.5301/hipint.5000071

15.Novais E.N., Clohisy J., Siebenrock K., Podeszwa D., Sucato D., Kim Y.J. Treatment of the symptomatic healed Perthes hip. Orthop. Clin. North. Am., 2011, vol. 42, no. 3, pp. 401-417. DOI: 10.1016/j.ocl.2011.05.003

16.Sankar W.N., Flynn J.M. The development of acetabular retroversion in children with Legg-Calvé-Perthes disease. J. Pediatr. Orthop., 2008, vol. 28, no. 4, pp. 440-443. DOI:10.1097/BPO.0b013e318168d97e

17.Myers S.R., Eijer H., Ganz R. Anterior femoroacetabular impingement after periacetabular osteotomy. Clin. Orthop. Relat. Res., 1999, no. 363, pp. 93-99.

18.Clohisy J.C., St. John L.C., Nunley R.M., Schutz A.L., Schoenecker P.L. Combined periacetabular and femoral osteotomies for severe hip deformities. Clin. Orthop. Relat. Res., 2009, vol. 467, no. 9, pp. 2221-2227. DOI: 10.1007/s11999-009-0810-1

19.Albers C.E., Steppacher S.D., Ganz R., Siebenrock K.A., Tannast M. Joint-preserving surgery improves pain, range of motion, and abductor strength after Legg-Calvé-Perthes disease. Clin. Orthop. Relat. Res., 2012, vol. 470, no. 9, pp. 2450-2461. DOI:10.1007/ s11999-012-2345-0

20.Ganz R., Horowitz K., Leunig M. Algorithm for femoral and periacetabular osteotomies in complex hip deformities. Clin. Orthop. Relat. Res., 2010, vol. 468, no. 12, pp. 3168-3180. DOI:10.1007/s11999-010-1489-z

21.Steppacher S.D., Tannast M., Werlen S., Siebenrock K.A. Femoral morphology differs between deficient and excessive acetabular coverage. Clin. Orthop. Relat. Res., 2008, vol. 466, no. 4, pp. 782-790. DOI: 10.1007/s11999-008-0141-7

22. Yasunaga Y., Yamasaki T., Ochi M. Patient selection criteria for periacetabular osteotomy or rotational acetabular osteotomy. Clin. Orthop. Relat. Res., 2012, vol. 470, no. 12, pp. 3342-3354. DOI: 10.1007/s11999-012-2516-z

23.Perry K.I., Trousdale R.T., Sierra R.J. Hip dysplasia in the young adult: an osteotomy solution. Bone Joint J., 2013, vol. 95-B, no. 11 Suppl. A, pp. 21-25. DOI: 10.1302/0301-620X.95B11.32633

24.Okano K., Enomoto H., Osaki M., Shindo H. Joint congruency as an indication for rotational acetabular osteotomy. Clin. Orthop. Relat. Res., 2009, vol. 467, no. 4, pp. 894-900. DOI: 10.1007/s11999-008-0443-9

25.Shore B.J., Novais E.N., Millis M.B., Kim Y.J. Low early failure rates using a surgical dislocation approach in healed Legg-CalvéPerthes disease. Clin. Orthop. Relat. Res., 2012, vol. 470, no. 9, pp. 2441-2449. DOI: 10.1007/s11999-011-2187-1

Received: 24.07 .2020

\section{Information about the authors:}

1. Mikhail P. Teplenky, M.D., Ph.D.,

Ilizarov National Medical Research Centre for Traumatology and Orthopedics, Kurgan, Russian Federation, Email: teplenkiymp@mail.ru

2. Evgenii V. Oleinikov, M.D., Ph.D., Ilizarov National Medical Research Centre for Traumatology and Orthopedics, Kurgan, Russian Federation, Email: orto-kgn@mail.ru

3. Vyacheslav S. Bunov, M.D., Ph.D.,

Ilizarov National Medical Research Centre for Traumatology and Orthopedics, Kurgan, Russian Federation, Email: bvsbunov@yandex.ru 